\title{
Weight change and incident metabolic syndrome in Iranian men and women; a 3 year follow-up study
}

\author{
Azadeh Zabetian ${ }^{1}$, Farzad Hadaegh ${ }^{* 1}$, Parvin Sarbakhsh ${ }^{1}$ and \\ Fereidoun Azizi²
}

Address: ${ }^{1}$ Prevention of Metabolic Disorders Research Center, Research Institute for Endocrine Sciences, Shaheed Beheshti University of Medical Sciences, Tehran, Iran and 2Endocrine Research Center, Research Institute for Endocrine Sciences, Shaheed Beheshti University of Medical Sciences, Tehran, Iran

Email: Azadeh Zabetian - zabetian@endocrine.ac.ir; Farzad Hadaegh* - fzhadaegh@endocrine.ac.ir; Parvin Sarbakhsh - p.sarbakhsh@gmail.com; Fereidoun Azizi - azizi@endocrine.ac.ir

* Corresponding author

Published: 13 May 2009

BMC Public Health 2009, 9:138 doi:10.1 I86/147|-2458-9-138
Received: 18 August 2008

Accepted: 13 May 2009

This article is available from: http://www.biomedcentral.com/I47I-2458/9//38

(c) 2009 Zabetian et al; licensee BioMed Central Ltd.

This is an Open Access article distributed under the terms of the Creative Commons Attribution License (http://creativecommons.org/licenses/by/2.0), which permits unrestricted use, distribution, and reproduction in any medium, provided the original work is properly cited.

\begin{abstract}
Background: Although the association of weight gain and developing metabolic syndrome (MetS) has been reported in the Western and Asian populations, data on the gender-stratified effects of weight change (including weight loss) on incident MetS and its components in the Middle East Caucasians is still scarce.

Methods: A total of $\mathrm{I} 43 \mathrm{I}$ men and 2036 women aged $\geq 20$ years with $\mathrm{BMI}>18.5 \mathrm{~kg} / \mathrm{m}^{2}$ were followed over 3 years. Multivariate logistic regression analysis was used to estimate the relative risk (RR) of MetS and its components (the Adult Treatment Panel III definition) associated with genderstratified quintiles of percent weight change. Subjects with MetS at baseline were excluded for analyzing the RR of MetS.
\end{abstract}

Results: There was $20.4 \%(95 \% \mathrm{Cl}, 19.6-21.2)$ age-adjusted incident MetS (18.4\% male vs. $23.1 \%$ women). In men, mild weight gain (WG) predicted high waist circumference (WC) and high triglyceride; moderate WG predicted MetS (RR 2.5, 95\% Cl I.4-4.3), high WC and high blood pressure (BP); large WG predicted MetS (RR 3.2, 95\% Cl I.8-5.7) and its components, except for high fasting plasma glucose. In women, mild WG predicted MetS (RR 2.5, 95\% Cl I.4-4.3), high WC and high BP; moderate WG predicted Mets (RR 4.6, 95\% Cl 2.7-8.0), high WC and high triglyceride; large WG predicted MetS (RR 6.6, 95\% Cl 3.8-II.3) and its components except for low HDL-cholesterol. Mild weight loss had protective effect on high WC in both genders and MetS in men (RR 0.5, 95\% Cl 0.26-0.97, $\mathrm{P}=0.04$ ).

Conclusion: Weight change showed different effects on MetS in men and women. In women, mild WG predicted MetS; however, mild weight loss was protective against MetS in men and high WC in both genders.

\section{Background}

The prevalence of overweight and obesity is increasing worldwide [1], and body weight is closely associated with mortality and morbidity [2,3]. Obesity has been known as an important risk factor of cardiovascular disease (CVD) [4] and weight reduction in overweight or obese individ- 
uals was known to have beneficial health effects [5]. It has been suggested that weight gain increases risk of developing hyperinsulinemia [6] and insulin resistance is an origin of metabolic syndrome (MetS) which is a strong risk factor of CVD [7]. Therefore, it seems that investigations on the association of weight change and MetS are essential to clarify the relationship between weight change and mortality.

Although self-reported weight gain is proven to be associated with the development of the MetS [8], only a few studies have prospectively assessed the impact of documented weight gain on MetS or its components $[6,9]$. Furthermore, not much published data is available about the effect of weight loss on MetS and its components [6,10$12]$.

On the other hand, body weight is a different entity among men and women [13] and the association between body mass index (BMI) and mortality was found to be different for men and women [14]. Therefore, to gain better knowledge about the weight gain epidemic and its adverse effect on MetS parameters, we believe that investigations stratified by gender need to be conducted.

Considering the high prevalence of MetS and the rising trend of obesity in our population $[15,16]$, we examined the impact of gender-stratified weight change on the risk of incident MetS and its components in participants of the Tehran Lipid and Glucose Study (TLGS) cohort during 3.1 years follow-up.

\section{Subjects}

This study was conducted within the framework of the TLGS, a population based prospective study conducted on residents of district 13 of Tehran, with the aim of determining the prevalence of noncommunicable disease-risk factors and developing a healthy lifestyle to decrease these risk factors [17]. In the TLGS, 15005 people aged 3 years and over, living in district 13 of Tehran were selected by a multistage cluster random sampling method; among them, were 10368 subjects aged $\geq 20$ years who participated in phase 1 (cross-sectional phase) from 1999-2001. After this phase, subjects were entered to the two, the cohort and the interventional groups. The cohort group consisted of 6437 subjects aged $\geq 20$ years and after excluding those with $\mathrm{BMI} \leq 18.5 \mathrm{~kg} / \mathrm{m}^{2}(\mathrm{n}=339)$ at baseline, 6098 subjects remained. From these, after further excluding subjects with missing data $(\mathrm{n}=112)$, death events $(n=120)$ and loss to follow up $(n=2399)$, there were 3467 subjects with full relevant data who underwent the second examination in phase 2 until September 2005 and entered to the current study (participation rate $\approx 57 \%$ ). The main reasons for non responders in the follow up study were either migration (30\%) or lack of con- tribution. The Ethical Committee of The Endocrine Research Center of Shahid Beheshti University (Medical Campus) approved the proposal of this study. Informed written consent was obtained from all subjects.

\section{Methods}

Subjects were interviewed privately, face-to-face, interviews being conducted by trained interviewers using pretested questionnaires. Initially, information on age, smoking habits, subjects' physical activity status, education level and medication use for treatment of diabetes, hypertension and lipid disorders was collected. Subjects with current or past history of smoking were called smokers and those who had never smoked were non smokers. Physical activity was categorized to three groups; vigorous, those who had hard physical activity (leisure time or occupational) at least three times a week; moderate, those who had hard physical activity at least once a week regularly; none, those without any regular hard physical activity. Education was categorized to three groups; Illiterate, under diploma and higher than diploma. Weight was measured, while subjects were minimally clothed without shoes using digital scales and recorded to the nearest 100 g. Height was measured in a standing position, without shoes, using tape stadimeter while shoulders were in a normal position. BMI was calculated as weight in kilograms divided by height in meters squared. Waist circumference (WC) was measured at the umbilical level, using unstretched tape meter, without any pressure to body surface, and was recorded to the nearest $0.1 \mathrm{~cm}$. To avoid inter subjective error; all measurements were taken by the same person. To measure blood pressure (BP), subjects were first made to rest for $15 \mathrm{~min}$, and then a qualified physician measured BP twice, during physical examinations in a seated position after one initial measurement for determining the peak inflation level using a standard mercury sphygmomanometer. There was at least a 30 -second interval between these two separate measurements, and thereafter the mean of the two measurements was considered as the participant's blood pressure. A blood sample was taken after 12-14 hour overnight fasting. Blood samples were taken in a sitting position according to the standard protocol and centrifuged within 30-45 min of collection. All blood analyses were done at the TLGS research laboratory on the day of blood collection. Fasting plasma Glucose (FPG) was measured by the enzymatic colorimetric method using glucose oxidize. For lipid measurements, triglyceride kit (Pars Azmoon Inc., Iran) was used. Triglyceride (TG) was assayed using enzymatic colorimetric tests with glycerol phosphate oxidize. HDL cholesterol (HDL-C) was measured after precipitation of the apolipoprotein $\mathrm{B}$ containing lipoproteins with phosphotungistic acid. Lipid standard (C.f.a.s., Boehringer Mannheim, Germany; cat. no. 759350) was used to calibrate the selectra 2 auto-analyzer for each day of 
laboratory analyses. All samples were analyzed when internal quality control met the acceptable criteria. Interand intra assay coefficients of variation (CV) for TG were less than $1.6 \%$ in the baseline, and less than $3.9 \%$ in the follow-up examination, respectively. The equivalent CVs for glucose were less than $2.2 \%$ at baseline, and less than $3.3 \%$ at follow-up examination, respectively. The method for glucose and lipid measurement was the same at both baseline and follow-up.

\section{Definition of Terms}

The MetS was defined according to the Adult Treatment Panel III (ATPIII) guidelines as the presence of three or more of the following [18]: (1) Abdominal obesity (high WC) as WC $>102 \mathrm{~cm}$ for men and $>88 \mathrm{~cm}$ for women, (2) High TG level ( $\geq 1.7 \mathrm{mmol} / \mathrm{l})$; (3) Low HDL-C level (< $1.03 \mathrm{mmol} / \mathrm{l}$ in men and $<1.29 \mathrm{mmol} / \mathrm{l}$ in women);(4) High BP [systolic blood pressure (SBP) $\geq 130$ or diastolic blood pressure (DBP) $\geq 85 \mathrm{~mm} \mathrm{Hg}$ )]; (5) High FPG concentration $(\geq 6.1 \mathrm{mmol} / \mathrm{l})$.

\section{Weight Change}

Percentage of weight change (PWC) during the 3.1 year follow-up was assessed in men and women of the study population separately. PWC was calculated as: [(Weight at phase 2 - Weight at phase1/Weight at phase1) $\times 100$ ]. Based on the distribution of weight change among both genders, the weight change percent was divided into quintiles, which resulted in a relatively similar number of subjects in each group as follows: Weight loss group [PWC <$1.3 \%$ men $(n=294),<-2.5 \%$ women $(n=404)]$; weight stable (referent group) [PWC -1.3 to $1.3 \%$ men $(\mathrm{n}=277)$, -2.5 to $1.2 \%$ women $(\mathrm{n}=412)]$; mild weight gain group [PWC 1.4 to $3.9 \%$ men $(\mathrm{n}=298), 1.3$ to $3.9 \%$ women $(\mathrm{n}$ $=401)$ ]; moderate weight gain group [PWC 4 to $6.9 \%$ men $(n=266), 4$ to $7.6 \%$ women $(n=391)]$; large weight gain group [PWC $\geq 7 \%$ men $(\mathrm{n}=296), \geq 7.7 \%$ women $(\mathrm{n}$ $=428)$ ].

\section{Data Analysis}

All data were analyzed by SPSS software package (SPSS Inc., Chicago, IL, USA; Version 15). Mean (SD) values or frequency (percentage) of baseline characteristics were expressed. The means and percents of the individual variables were compared between baseline and follow-up groups, by using paired t-test and McNemar test, respectively. General Linear Model was used to estimate means of individual MetS parameters at the 3.1 year follow up examination according to 5 PWC groups adjusted for age, baseline weight, smoking status, physical activity, education level, medication use for treatment of diabetes, hypertension and lipid disorders and the corresponding parameter, at baseline. To elucidate the difference and similarity of the effects of PWC according to gender, subjects were stratified into 2 groups by gender. For MetS and each of its components, relative risk (RR) and the 95\% confidence intervals (CI) according to the gender-stratified quintiles of PWC were calculated after adjustments of age, baseline weight, smoking status, physical activity, education level and medication use for treatment of diabetes, hypertension and lipid disorders. The second quintile of PWC, which was called the stable group, was considered as the reference. To examine the RR of developing MetS and its components, logistic models were fitted separately in subject who did not have MetS or its components at baseline, respectively.

\section{Results}

In comparison to the subjects who did not attend the follow-up visit, those who attended had higher values of age (44. vs. 40.8 years), BMI (27. 3 vs. $\left.26.5 \mathrm{~kg} / \mathrm{m}^{2}\right), \mathrm{WC}(89.2$ vs. $87 \mathrm{~cm}$ ), SBP (120.8 vs. $118.9 \mathrm{mmHg}$ ), DBP (78. 6 vs. $77.5 \mathrm{mmHg}$ ), FPG (5.5 vs. $5.4 \mathrm{mmol} / \mathrm{l}$ ), TG (2 vs. 1.8 $\mathrm{mmol} / \mathrm{l})$, (all p values $<0.05)$. However, there was no difference in HDL-C levels between participants vs. nonparticipants.

The current analysis included 3467 subjects (1431 male and 2036 female, sex ratio $\mathrm{M}: \mathrm{W}=0.7$ ) with a mean (SD) age of 44.4 (14.2) years. At baseline, the average BMI was $27.3(4.4) \mathrm{kg} / \mathrm{m}^{2}$, normally distributed. Also, 31.9\% of the total participants had normal weight (BMI $18.5-24.99 \mathrm{~kg} /$ $\mathrm{m}^{2}$ ), 42.5\% were overweight (BMI $25-29.99 \mathrm{~kg} / \mathrm{m}^{2}$ ) and $25.6 \%$ were obese $\left(\mathrm{BMI} \geq 30 \mathrm{~kg} / \mathrm{m}^{2}\right)$. After a mean 3.1 years of follow-up, range of 9 months to 6 years, the cohort gained a mean weight of $1.9 \mathrm{~kg}$ with a range of -28 to $+39 \mathrm{~kg}$ of weight change, and the prevalence of overweight and obesity increased to $43.3 \%$ and $31.3 \%$, respectively (Data not shown). As shown in Table 1 all of the anthropometric and metabolic parameters were higher after follow-up except serum TG levels, HDL-C, SBP and DBP. Medication use for dyslipidemia in males and for hypertension and diabetes in both genders were more prevalent at follow-up. There were more smokers in both genders after follow-up. At baseline, $26 \%$ of participants had vigorous and 59.9\% had low physical activity. Also, $10.7 \%$ of study population was illiterate and $77.7 \%$ of those had under diploma education. Among men, we found 394 subjects with MetS at baseline and 484 MetS cases at the follow up; however from the latter, 274 subjects overlapped with baseline cases, with 210 new cases of MetS remained. Among women, we found 856 subjects with MetS at baseline and 969 MetS cases at the follow up, of which 699 subjects overlapped with baseline cases, hence 270 new cases of MetS remained. Therefore, from among the 2217 participants free of MetS at baseline we had 480 (210 men and 270 women) new cases of MetS during 3.1 years follow up. The age-adjusted (Iran census, 2006 ) incidence of MetS was 20.4\% (95\% CI, 19.6-21.2) in the total population. Incident MetS was found to be 
Table I: General characteristic of the study participants at the baseline examination and follow-up by gender*

\begin{tabular}{|c|c|c|c|c|c|c|}
\hline \multirow[b]{2}{*}{ General characteristics } & \multicolumn{3}{|c|}{ Men $(n=|43|)$} & \multicolumn{3}{|c|}{ Women $(n=2036)$} \\
\hline & At baseline & At follow-up & $P$ value & At baseline & At follow-up & $P$ value \\
\hline Age (year) & $45.7 \pm 14.9$ & $48.9 \pm 14.8$ & $<0.001$ & $43.5 \pm 13.6$ & $46.8 \pm 13.6$ & $<0.001$ \\
\hline Weight (kg) & $75.4 \pm 12.3$ & $77.6 \pm 12.7$ & $<0.001$ & $68.8 \pm 11.8$ & $70.5 \pm 12.0$ & $<0.001$ \\
\hline BMI $\left(\mathrm{kg} / \mathrm{m}^{2}\right)$ & $26.2 \pm 3.8$ & $26.8 \pm 3.9$ & $<0.001$ & $28.1 \pm 4.6$ & $29.1 \pm 4.8$ & $<0.001$ \\
\hline$W C(\mathrm{~cm})$ & $89.8 \pm 10.8$ & $95.4 \pm 10.3$ & $<0.001$ & $89 \pm 12.2$ & $92.8 \pm 12.3$ & $<0.001$ \\
\hline FPG $(\mathrm{mmol} / \mathrm{l})$ & $5.4 \pm 1.5$ & $5.6 \pm 1.7$ & $<0.001$ & $5.6 \pm 2.1$ & $5.7 \pm 2.2$ & $<0.001$ \\
\hline Triglyceride $(\mathrm{mmol} / \mathrm{l})$ & $2.1 \pm 1.4$ & $2 \pm 1.3$ & $<0.001$ & $1.9 \pm 1.2$ & $1.8 \pm 1.2$ & $<0.001$ \\
\hline HDL-C (mmol/l) & $1.0 \pm 0.2$ & $0.9 \pm 0.2$ & $<0.001$ & $1.2 \pm 0.3$ & $\mathrm{I} \pm 0.2$ & $<0.001$ \\
\hline SBP (mmHg) & $122.3 \pm 19.1$ & $120.2 \pm 18.5$ & $<000.1$ & $119.9 \pm 19.4$ & $1 \mid 8.2 \pm 20.1$ & $<0.001$ \\
\hline $\mathrm{DBP}(\mathrm{mmHg})$ & $78.6 \pm 11.0$ & $75.7 \pm 11.1$ & $<0.001$ & $78.6 \pm 10.3$ & $75.8 \pm 10.1$ & $<0.001$ \\
\hline ATPIII MetS, no (\%) & 394 (27.5) & $484(33.8)$ & $<0.001$ & $856(42)$ & $969(47.6)$ & $<0.001$ \\
\hline Smokers, no (\%) & $574(40.4)$ & $628(44.2)$ & $<0.001$ & III (5.5) & $138(6.8)$ & $<0.001$ \\
\hline \multicolumn{7}{|l|}{ Medication for, no (\%) } \\
\hline Dyslipidemia & $31(2.2)$ & $43(3.0)$ & $<0.001$ & II | (5.5) & $10 \mid(5.0)$ & $<0.001$ \\
\hline Hypertension & $94(6.6)$ & $95(6.7)$ & $<0.001$ & $235(11.6)$ & $270(13.3)$ & $<0.001$ \\
\hline Diabetes & $39(2.7)$ & $68(4.8)$ & $<0.001$ & $109(5.4)$ & $158(7.8)$ & $<0.001$ \\
\hline
\end{tabular}

* Plus, minus represents mean \pm standard deviation

BMI: body mass index, WC: waist circumference, FPG: fasting plasma glucose, SBP: systolic blood pressure, DBP: diastolic blood pressure

Smokers are those with current or past history of smoking.

ATPIII defined Mets: metabolic syndrome by the ATPIII definition which is indicated in reference 18.

Table 2: Adjusted means of the metabolic physiological parameters by weight change groups after 3 years follow-up*

\begin{tabular}{|c|c|c|c|c|c|c|}
\hline \multirow[b]{2}{*}{$\begin{array}{l}\text { Metabolic } \\
\text { parameters }\end{array}$} & \multicolumn{5}{|c|}{ Gender-stratified percentage of weight change ${ }^{\dagger}$} & \multirow[b]{2}{*}{$P$ value } \\
\hline & $\begin{array}{l}\text { Loss group } \\
(294 \mathrm{M} ; 404 \mathrm{~W})\end{array}$ & $\begin{array}{l}\text { Stable group } \\
(277 \mathrm{M} ; 412 \mathrm{~W})\end{array}$ & $\begin{array}{l}\text { Mild gain group } \\
(298 \mathrm{M} ; 401 \mathrm{~W})\end{array}$ & $\begin{array}{l}\text { Moderate gain group } \\
(266 \mathrm{M} ; 391 \mathrm{~W})\end{array}$ & $\begin{array}{l}\text { Large gain group } \\
(296 \mathrm{M} ; 428 \mathrm{~W})\end{array}$ & \\
\hline \multicolumn{7}{|l|}{ Men $(n=|43|)$} \\
\hline WC $(\mathrm{cm})$ & $90.8(0.5)$ & $93.7(0.5)$ & $95.3(0.5)$ & $96.8(0.5)$ & $100.5(0.5)$ & $<0.001$ \\
\hline TG $(\mathrm{mmol} / \mathrm{l})$ & $1.9(0.1)$ & $2(0.1)$ & $2.2(0.1)$ & $2.3(0.1)$ & $2.6(0.1)$ & $<0.001$ \\
\hline $\mathrm{FPG}(\mathrm{mmol} / \mathrm{l})$ & $6.9(0.2)$ & $6.8(0.2)$ & $6.9(0.2)$ & $6.9(0.2)$ & $6.9(0.2)$ & 0.7 \\
\hline $\begin{array}{l}\mathrm{HDL}-\mathrm{C} \\
(\mathrm{mmol} / \mathrm{l})\end{array}$ & $0.88(0.02)$ & $0.85(0.02)$ & $0.86(0.02)$ & $0.83(0.02)$ & $0.080(0.02)$ & 0.001 \\
\hline $\mathrm{SBP}(\mathrm{mmHg})$ & $119.8(1.7)$ & $121.9(1.8)$ & I23.5 (I.8) & $124.6(1.8)$ & I25.6 (I.8) & $<0.001$ \\
\hline $\mathrm{DBP}(\mathrm{mmHg})$ & $74.4(1.2)$ & $75.4(1.2)$ & $76.2(1.2)$ & $77.3(1.2)$ & $77.7(1.2)$ & $<0.001$ \\
\hline \multicolumn{7}{|l|}{$\begin{array}{l}\text { Women } \\
(n=2036)\end{array}$} \\
\hline WC $(\mathrm{cm})$ & $87.3(0.5)$ & $90.9(0.5)$ & $93.2(0.5)$ & $94.5(0.5)$ & $98.5(0.5)$ & $<0.001$ \\
\hline TG $(\mathrm{mmol} / \mathrm{l})$ & $1.9(0.07)$ & $2.1(0.07)$ & $2.1(0.07)$ & $2.2(0.07)$ & $2.4(0.07)$ & $<0.001$ \\
\hline $\mathrm{FPG}(\mathrm{mmol} / \mathrm{l})$ & $6.6(0.1)$ & $6.4(0.1)$ & $6.5(0.1)$ & $6.5(0.1)$ & $6.6(0.1)$ & 0.2 \\
\hline $\begin{array}{l}\mathrm{HDL}-\mathrm{C} \\
(\mathrm{mmol} / \mathrm{l})\end{array}$ & $1.05(0.02)$ & $1.04(0.02)$ & $1.01(0.02)$ & $1.01(0.02)$ & $0.99(0.02)$ & 0.003 \\
\hline $\mathrm{SBP}(\mathrm{mmHg})$ & $118.7(1.2)$ & $119.9(1.2)$ & $123(1.2)$ & $122.9(1.2)$ & |25.| (1.2) & $<0.001$ \\
\hline $\mathrm{DBP}(\mathrm{mmHg})$ & $74.9(0.7)$ & $76.1(0.7)$ & $77.2(0.7)$ & $77.2(0.7)$ & $78.6(0.7)$ & $<0.001$ \\
\hline
\end{tabular}

* Means were adjusted for age, baseline weight, smoking, physical activity, education level, medication use plus the corresponding variable at baseline; numbers in the parentheses present standard error.

† The gender-stratified percentage of weight change were grouped as follow: weight loss group $(<-1.3 \%$ men, $<-2.5 \%$ women); weight stable group (-I.3 to I.3\% men, -2.5 to I.2\% women); mild weight gain group (I.4 to $3.9 \%$ men, I.3 to $3.9 \%$ women); moderate weight gain group (4 to $6.9 \%$ men, 4 to $7.6 \%$ women); large weight gain group ( $\geq 7 \%$ men, $\geq 7.7 \%$ women).

BMI: body mass index, WC: waist circumference, TG: triglyceride, FPG: fasting plasma glucose, SBP: systolic blood pressure, DBP: diastolic blood pressure 
higher in women $23.1 \%(22.3-24)$ than in men $18.4 \%$ (17.6-19.1), $\mathrm{P}<0.001$.

Table 2 showed means of the MetS parameters by genderstratified PWC quintiles after adjustment of previously mentioned covariates. In both genders there was a strong linear trend of weight gain and worsening of all MetS parameters, except for the FPG level. Furthermore, the age adjusted incidence $(95 \% \mathrm{CI}$ ) of MetS by gender-stratified PWC quintiles among the 2217 participants free of MetS at baseline were as followed; weight loss group, $8.6 \%$ (8.0-9.1) in men and $10.2 \%(9.6-10.8)$ in women; weight stable group, $20 \%(16.2-17.7)$ in men and $12.2 \%$ (11.5-12.8) in women; mild weight gain group, $17.1 \%$ (16.3-17.8) in men and 23.4\% (22.6-24.3) in women; moderate weight gain group, $24.7 \%(23.8-25.5)$ in men and $31.6 \%$ (30.7-32.5) in women; large weight gain group, $22.7 \%(21.9-23.5)$ in men and $30.6 \%$ (29.7-31.5) in women.

Table 3 and Figure 1 showed the adjusted RR (95\% CI) of the ATPIII defined MetS and its components according to the weight change groups in men. Mild increase in weight predicted high WC and high TG components, while moderate increase was associated with high WC, high BP components and incident MetS. In this gender, large weight gain predicted MetS and all of its components except high FPG. Weight loss had protective effect on the MetS with the RR 0.5 (95\% CI $0.3-1.0)$ and high WC component with the RR 0.3 (95\% CI 0.1-0.6).
The same analyses in women were shown in Table 4 and Figure 1. In this gender group, increasing weight in any category predicted MetS with the RR ranging from 2.5 (95\% CI 1.4-4.3) for mild to 6.6 (95\% CI 3.8-11.3) for large weight gain. Mild weight gain showed association with high WC and high BP components and moderate weight gain predicted high WC and high TG components. Large weight gain predicted all components except low HDL-C, on the other hand weight loss found to be protective only against high WC component. Regarding the effect of age on the relationship between weight gain and MetS, especially in women, we divided women participants into those aged $>50$ years and $\leq 50$ years; the analysis according to this classification highlighted that in women $\leq 50$ years the high $\mathrm{BP}$ component was not affected by weight gain. However, in those older than 50 years the RRs of high WC and high BP considering weight gain groups, were increased significantly (data not shown).

As it is possible that using medication could affect the association of weight change and MetS components, we also performed analyses limited to subjects not treated for hypertension, dyslipidemia or diabetes. Results were unchanged after excluding subjects treated with medications (data not shown). Furthermore, when we adapted the American Heart Association/National Heart, Lung, and Blood Institute definition of MetS [19] [which considered medication treatment in MetS components classification] in place of original NCEP/ATP III, the results remained unchanged (data not shown).

Table 3: Adjusted relative risk of ATPIII-defined metabolic syndrome components by weight change groups in men ( $n=\mid 431$ )*

\begin{tabular}{|c|c|c|c|c|c|}
\hline & \multicolumn{5}{|c|}{ Percentage of weight change } \\
\hline & Loss group (<-I.3\%) & $\begin{array}{l}\text { Stable group } \\
\text { (-1.3 to } 1.3 \%)\end{array}$ & $\begin{array}{l}\text { Mild gain group } \\
\text { (1.4 to } 3.9 \%)\end{array}$ & $\begin{array}{l}\text { Moderate gain group } \\
\text { (4 to } 6.9 \% \text { ) }\end{array}$ & Large gain group ( $\geq 7 \%$ ) \\
\hline High WC & $0.3(0.1-0.6)$ & Reference & $2.4(1.3-4.4)$ & $4.4(2.4-8.0)$ & $9.2(4.8-17.5)$ \\
\hline No. of subjects $\dagger$ & 255 & 236 & 263 & 240 & 276 \\
\hline$P$ value & 0.001 & & 0.005 & $<0.001$ & $<0.001$ \\
\hline High TG & $0.8(0.4-1.9)$ & Reference & $2.2(I . I-4.5)$ & $1.9(0.9-3.8)$ & $3.8(1.9-7.7)$ \\
\hline No. of subjects ${ }^{\dagger}$ & 111 & 103 & 116 & 126 & 168 \\
\hline$P$ value & 0.7 & & 0.03 & 0.08 & $<0.001$ \\
\hline Low HDL-C & $0.8(0.4-1.4)$ & Reference & $0.9(0.5-1.6)$ & $1.3(0.7-2.5)$ & $1.9(1.0-3.4)$ \\
\hline No. of subjects ${ }^{\dagger}$ & 99 & 93 & 108 & 94 & 117 \\
\hline$P$ value & 0.4 & & 0.8 & 0.3 & 0.04 \\
\hline High FPG & $0.5(0.2-1.2)$ & Reference & I.4 (0.7-2.8) & $1.2(0.6-2.5)$ & I.3 (0.6-2.9) \\
\hline No. of subjects $\dagger$ & 236 & 234 & 265 & 248 & 281 \\
\hline$P$ value & 0.1 & & 0.3 & 0.6 & 0.4 \\
\hline High BP & I.2(0.6-2.7) & Reference & I.8 (0.8-3.7) & $2.7(1.3-5.6)$ & $3.4(1.7-7.1)$ \\
\hline No. of subjects $\dagger$ & 155 & 160 & 175 & 176 & 225 \\
\hline$P$ value & 0.6 & & 0.1 & 0.007 & 0.001 \\
\hline
\end{tabular}

* Relative risks $(95 \% \mathrm{Cl})$ were adjusted for age, baseline weight, smoking, physical activity, education level and medication use. t Only subjects free of mentioned component at baseline were entered in each analysis.

WC: waist circumference, TG: triglyceride, FPG: fasting plasma glucose, BP: blood pressure 


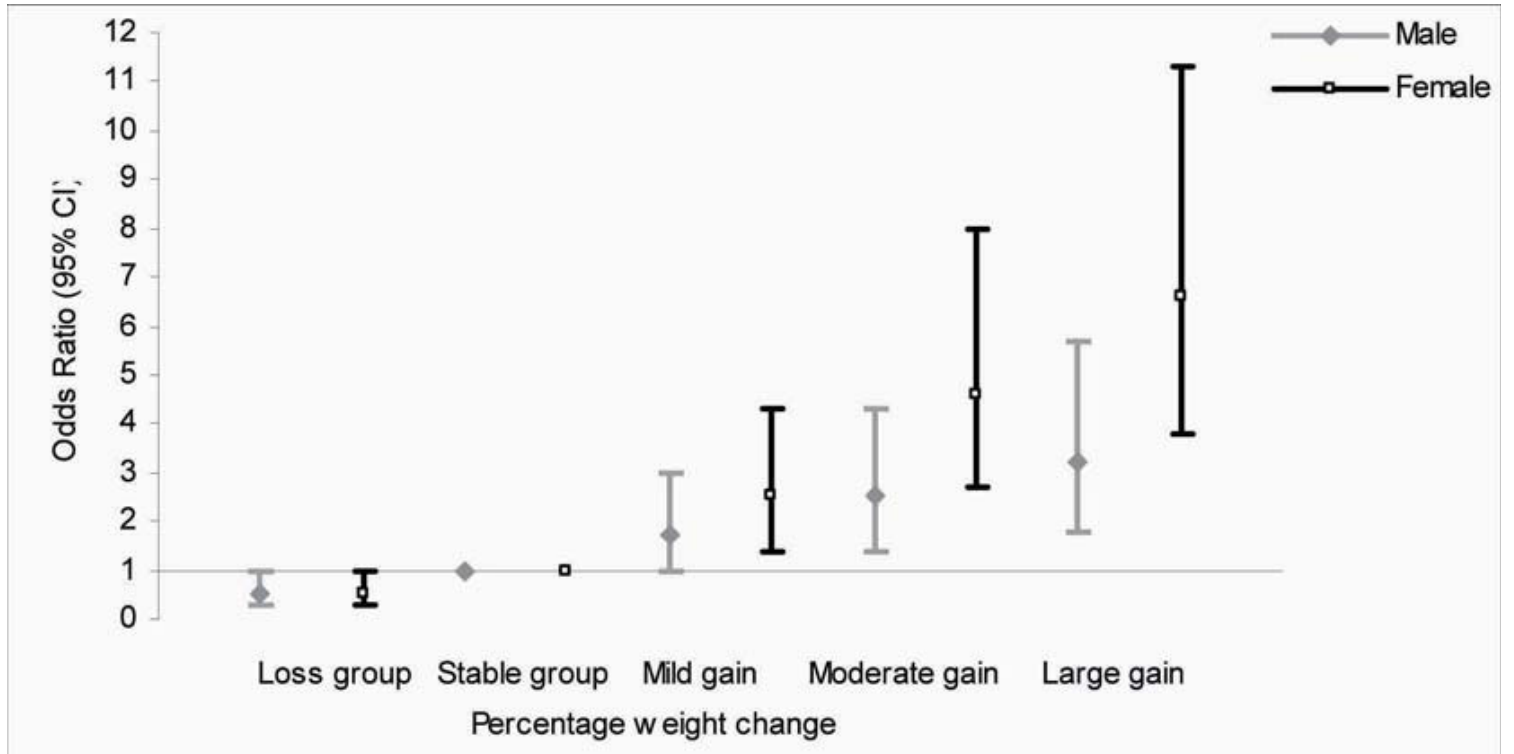

\section{Figure I}

Adjusted relative risk of metabolic syndrome by weight change groups in both genders. From the total study population (I43I men and 2036 women), only 1037 men and I 80 women who were free of metabolic syndrome at baseline included in this logistic regression model. The model was adjusted for age, baseline weight, smoking, physical activity, education level and medication use. The gender-stratified percentage of weight change (PWC) was shown in the $X$ axis, grouped as follow: weight loss group $[<-1.3 \%$ men $(n=191),<-2.5 \%$ women $(n=193)]$; weight stable group $[-1.3$ to $1.3 \%$ men $(n=185),-2.5$ to I.2\% women $(n=204)$ ]; mild weight gain group [1.4 to $3.9 \%$ men $(n=209), 1.3$ to $3.9 \%$ women $(n=228)$ ]; moderate weight gain group [4 to $6.9 \%$ men $(n=204), 4$ to $7.6 \%$ women $(n=233)$ ]; large weight gain group [ $=7 \%$ men $(n=248)$, $=7.7 \%$ women $(\mathrm{n}=322)]$. The stable group was considered as reference. Relative risk $(95 \% \mathrm{Cl})$ for ATPIII defined metabolic syndrome according to PWC groups was shown in the $Y$ axis.

\section{Discussion}

In this population based study of Iranian urban residents, we showed that in men, more than a moderate increase in weight ( $>4 \%$ of the baseline weight) predicted incident MetS, and weight reduction of at least $1.3 \%$ of initial body weight plays a protective effect against this syndrome. In women increase in weight, even a mild increase in a short term follow-up (> $1.3 \%$ of the initial weight), was associated with an increased risk of incident MetS. In both genders weight loss was protective against high WC component.

There was a 20.6\% age-adjusted incident of MetS in our study, which was accompanied by $3.8 \%$ incident Type 2 diabetes (FPG $\geq 7 \mathrm{mmol} / \mathrm{l}$ or medication use) (data not shown). Onat et al in a representative population of Turkish adults, with a high prevalence of MetS, showed incident cases of MetS in $225(23 \%)$ men and $252(\approx 25 \%)$ women over a mean follow up of 5.9 years [20,21]. In a 4 year cohort of 9785 Taiwanese adults, there was $17.5 \%$ incidence of MetS in men versus $8.3 \%$ women, using modified ATPIII definition [22]. Also in non diabetic American Indians, who were free of MetS at baseline, $37.7 \%$ got the ATPIII defined syndrome at 10 -year follow up [23]. The European Lacidipine Study on Atherosclerosis showed $21.4 \%$ incident MetS in hypertensive subjects aged 45-75 years, after 3.7 years follow-up [24].

The effect of weight change on MetS has been proposed to be caused by insulin resistance; it has been also suggested that insulin resistance may lead to MetS through accommodation of adiposity [25]. Weight gain was associated with developing the insulin resistance syndrome in one cross-sectional study on the Finish middle-aged men [8]. The same association of weight gain with incident ATPIII defined MetS was found in the adult American population [26]. Since the aim of this study was descriptive, we did not make large multivariate analyses; so it would have been difficult to interpret the higher incident of MetS in women. However, in a multi center study in different ethnic groups, using signal detection analysis, the best predictor of incident metabolic syndrome was waist circumference [27]. Hence, regarding the high prevalence of abdominal obesity in Iranian females [28]; the higher relative risk for incident metabolic syndrome in this group could be justifiable. The linear association of weight gain with MetS parameters (except FPG) in our study was comparable to the Hiller et al. study, which showed the same 
Table 4: Adjusted relative risk of ATPIII-defined metabolic syndrome components by weight change groups in women $(n=2036) *$

\begin{tabular}{|c|c|c|c|c|c|}
\hline \multirow[b]{2}{*}{$\begin{array}{l}\text { Metabolic syndrome } \\
\text { components }\end{array}$} & \multicolumn{5}{|c|}{ Percentage of weight change } \\
\hline & Loss group $(<-2.5 \%)$ & $\begin{array}{l}\text { Stable group } \\
(-2.5 \text { to } 1.2 \%)\end{array}$ & $\begin{array}{l}\text { Mild gain group } \\
\text { (1.3 to } 3.9 \%)\end{array}$ & $\begin{array}{l}\text { Moderate gain group } \\
\text { (4 to } 7.6 \% \text { ) }\end{array}$ & $\begin{array}{l}\text { Large gain group }(\geq \\
7.7 \%)\end{array}$ \\
\hline High WC & $0.3(0.2-0.7)$ & Reference & $1.9(1.1-3.2)$ & $2.8(1.6-5.0)$ & $7.3(4.1-13.0)$ \\
\hline No. of subjects $\dagger$ & 149 & 162 & 206 & 192 & 286 \\
\hline$P$ value & .003 & & .03 & $<0.001$ & $<0.001$ \\
\hline High TG & $0.7(0.4-1.2)$ & Reference & $1.2(0.7-2.1)$ & $2.1(1.3-3.6)$ & $2.7(1.7-4.4)$ \\
\hline No. of subjects $\dagger$ & 173 & 201 & 202 & 204 & 294 \\
\hline$P$ value & 0.2 & & 0.5 & 0.003 & $<0.001$ \\
\hline Low HDL-C & $0.7(0.4-1.2)$ & Reference & $0.9(0.5-1.6)$ & I.I (0.6-2.0) & $\mathrm{I} .5(0.8-2.7)$ \\
\hline No. of subjects ${ }^{\dagger}$ & 101 & 107 & 96 & 99 & 119 \\
\hline$P$ value & 0.2 & & 0.7 & 0.7 & 0.2 \\
\hline High FPG & $0.7(0.3-1.6)$ & Reference & $1.6(0.8-3.1)$ & $1.5(0.7-2.9)$ & $4.3(2.2-8.2)$ \\
\hline No. of subjects $\dagger$ & 307 & 339 & 340 & 358 & 396 \\
\hline$P$ value & 0.4 & & 0.1 & 0.3 & $<0.001$ \\
\hline High BP & $0.9(0.5-1.8)$ & Reference & $2(1.1-3.5)$ & I.3 (0.7-2.5) & $2.1(1.1-3.7)$ \\
\hline No. of subjects ${ }^{\dagger}$ & 244 & 240 & 256 & 263 & 338 \\
\hline$P$ value & 0.9 & & 0.02 & 0.3 & 0.01 \\
\hline
\end{tabular}

* Relative risks $(95 \% \mathrm{Cl})$ were adjusted for age, baseline weight, smoking, physical activity, education level and medication use.

t Only subjects free of mentioned component at baseline were entered in each analysis.

WC: waist circumference, TG: triglyceride, FPG: fasting plasma glucose, BP: blood pressure

association with each of the metabolic physiological continuous measures [6]. Nevertheless, we found a significant decrease in BP, TG and HDL-C during this short term follow up. However, favorable trends in TG and BP were not enough to alleviate the risk of MetS in light of the increasing trend in general and central obesity. Recently, in a non-diabetic population, we showed that despite an increasing trend in general and abdominal obesity, a favorable trend in total cholesterol in both genders and TG in men occurred, which was not related to the increasing usage of lipid lowering drugs. However, this trend was counterbalanced by unfavorable changes in HDL cholesterol, which was found to decrease in both genders especially in men [15]. Similar declining trends in lipoprotein level in light of the increasing trends in obesity were also reported in U.S adult population [29].

Weight loss has been recognized to have beneficial effects on several cardiovascular risk factors [30,31]. Some studies have also shown that weight loss is followed by an improvement of glucose tolerance and a reduced risk of type 2 diabetes [32,33]. Villareal et al. have found that in older obese adults the diet-induced weight loss ( $\approx 9 \%$ of initial body weight) during 6 months, could improve most of the obesity-related CHD risk factors including high WC [34]. Recently, Alhassan et al. reported that $\geq 7 \%$ reduction in body weight has a beneficial impact on MetS variables [35]. In our data analysis, weight loss of $>1.3 \%$ of initial weight reduced risk of MetS [RR 0.5, 95\%CI (0.3-1.0)] in men; furthermore a mild weight loss decreased risk of the high WC component in both genders.
In our study, weight gain increased the risk of high FPG in women, but not in men. Considering the observational nature of our study, delineating the reason for this divergence between genders regarding weight gain and risk of abnormal glucose metabolism was difficult. However, in Turkish adults with a similar prevalence of MetS, women with normal glucose metabolism were more prone to incident dibetes than men [36]. Furthermore, in a recent population based study from Denmark, women who had gained and sustained considerable weight were more susceptible to development of new onset diabetes [37]. During the short term follow-up in our study, attained BMI (in phase 2) and BMI changes were more marked in women than men (mean of BMI change: 0.99 vs. $0.66 \mathrm{~kg} /$ $\mathrm{m}^{2} ; \mathrm{P}<0.001$, respectively). On the other hand, body weight is a stronger predictor of Type 2 diabetes than physical activity, considering the finding that physical activity was significantly lower in Iranian women than men $[38,39]$. Hence, the higher prevalence of diabetes and abnormal glucose metabolism (i.e. impaired fasting glucose or impaired glucose tolerance) in Iranian women than in men was justifiable [40].

Overall we also found the association of high BP component with weight gain in both genders. Furthermore, the synergistic contribution of insulin resistance and menopause to components of the metabolic syndrome was reported recently with SBP, DBP and WC [41], this may explain the accelerated impact of weight gain on abdominal obesity and blood pressure among women aged $\geq 50$ in the current study. In a cohort study of adult men, an 
increased in BMI was found to be associated with an increased risk of hypertension and weight loss did not affect risk of hypertension significantly [9].

The results of our study are difficult to compare with other studies conducted on the association of weight change and cardiovascular risk factors because of differences in the time period between the two weight measures, the length of follow up, and how weight change is expressed. There are some other points that should be considered when examining the results of our study. First, about $43 \%$ of the baseline participants were excluded from cohort analysis because of loss to follow-up or missing data. This group was healthier in their baseline characteristic assessments; hence we may have overestimated the incidence of metabolic syndrome in the general population. Second, our findings were derived from an observational prospective study; so we did not have information on whether weight loss in this cohort was intentional or unintentional. Finally it must be emphasized that the conclusions drawn from this study were determined in Middle East Caucasian residents in the capital city of Iran and further studies should be conducted to determine whether our findings can apply to other populations of this region.

Among the existing studies addressing the relationship between weight change and MetS, only a few have analyzed their data on the longitudinal effects of weight change adjusting for confounding variables $[7,10]$. We were also able to adjust for several important confounding variables and to explore the effects of different weight change groups in separate genders. Moreover, we used anthropometric variables that were directly measured by trained medical professionals rather than self-reported or self-measured anthropometrics.

\section{Conclusion}

In this population based cohort study we found a strong positive association of weight gain and increased risk of MetS, especially in women. Furthermore, weight loss had protective effects on the incident MetS in men and high WC component in both genders. Along with previous findings, these data suggest that promoting weight control in the Iranian population is crucial to prevent increasing risk of MetS.

\section{Competing interests}

The authors declare that they have no competing interests.

\section{Authors' contributions}

AZ participated in conception and design of the study, performing the statistical analysis and drafting the manuscript. FH participated in the conception and design of the study, drafting the manuscript, critical revision and its final approval. PS participated in the statistical analysis of the study. FA participated in its design and coordination. All authors read and approved the final manuscript.

\section{Acknowledgements}

This study was supported by Grant No. 12I from the National Research Council of the Islamic Republic of Iran. We express appreciation to Dr.

Mohammad Reza Bozorgmanesh, Ms. Nilufar Shiva and the participants of district 13, Tehran, for their enthusiastic support in this study.

\section{References}

I. Seidell JC: Obesity: a growing problem. Acta Paediatr Suppl I999, 88:46-50.

2. Shaper AG, Wannamethee SG, Walker M: Body weight: implications for the prevention of coronary heart disease, stroke, and diabetes mellitus in a cohort study of middle aged men. BMJ 1997, 3 I4:13II-7.

3. Seidell JC, Verschuren WM, van Leer EM, Kromhout D: Overweight, underweight, and mortality. A prospective study of 48,287 men and women. Arch Intern Med 1996, I 56:958-63.

4. Washio M, Hayashi R, Fukuoka Heart Study Group: Past history of obesity (overweight by WHO criteria) is associated with an increased risk of nonfatal acute myocardial infarction: a case-control study in Japan. Circ J 2004, 68:4I-6.

5. Su HY, Sheu WH, Chin HM, Jeng CY, Chen YD, Reaven GM: Effect of weight loss on blood pressure and insulin resistance in normotensive and hypertensive obese individuals. Am J Hyperten 1995, 8:1067-7|.

6. Hillier TA, Fagot-Campagna A, Eschwège E, Vol S, Cailleau M, Balkau $B$ : the D.E.S.I.R. Study group. Weight change and changes in the metabolic syndrome as the French population moves towards overweight: the D.E.S.I.R. cohort. Int J Epidemiol 2006, 35:190-6.

7. Ferrannini E, Haffner SM, Mitchell BD, Stern MP: Hyperinsulinaemia: the key feature of a cardiovascular and metabolic syndrome. Diabetologia 1991, 34:416-22.

8. Everson SA, Goldberg DE, Helmrich SP, Lakka TA, Lynch JW, Kaplan GA, Salonen JT: Weight gain and the risk of developing insulin resistance syndrome. Diabetes Care 1998, 21:1637-43.

9. Ishikawa-Takata K, Ohta T, Moritaki K, Gotou T, Inoue S: Obesity, weight change and risks for hypertension, diabetes and hypercholesterolemia in Japanese men. Eur J Clin Nutr 2002, 56:60I-7.

10. Case CC, Jones PH, Nelson K, O'Brian Smith E, Ballantyne CM: Impact of weight loss on the metabolic syndrome. Diabetes Obes Metab 2002, 4:407-I4.

II. Filippatos TD, Kiortsis DN, Liberopoulos EN, Georgoula M, Mikhailidis DP, Elisaf MS: Effect of orlistat, micronised fenofibrate and their combination on metabolic parameters in overweight and obese patients with the metabolic syndrome: the FenOrli study. Curr Med Res Opin 2005, 2 1: 1997-2006.

12. Orchard TJ, Temprosa M, Goldberg R, Haffner S, Ratner R, Marcovina $S$, Fowler S, Diabetes Prevention Program Research Group: The effect of metformin and intensive lifestyle intervention on the metabolic syndrome: the Diabetes Prevention Program randomized trial. Ann Intern Med 2005, 1 42:6 I I-9.

13. Everson SA, Goldberg DE, Helmrich SP, Lakka TA, Lynch JW, Kaplan GA, Salonen JT: The effect of sex, age and race on estimating percentage body fat from body mass index: The Heritage Family Study. Int J Obes Relat Metab Disord 2002, 26:789-96.

14. Lahmann PH, Lissner L, Gullberg B, Berglund G: A prospective study of adiposity and all-cause mortality: the Malmö Diet and Cancer Study. Obes Res 2002, I0:361-9.

15. PJ.Bozorgmanesh MR, Hadaegh F, Padyab M, Mehrabi Y, Azizi F: Temporal changes in anthropometric parameters and lipid profile according to body mass index among an adult Iranian urban population. Ann Nutr Metab 2008, 53:13-22.

16. Zabetian A, Hadaegh F, Azizi F: Prevalence of metabolic syndrome in Iranian adult population, concordance between the IDF with the ATPIII and the WHO definitions. Diabetes Res Clin Pract 2007, 77:25I-7.

17. Azizi F, Rahmani M, Emami H, Mirmiran P, Hajipour R, Madjid M, Ghanbili J, Ghanbarian A, Mehrabi Y, Saadat N, Salehi P, Mortazavi N, Heydarian P, Sarbazi N, Allahverdian S, Saadati N, Ainy E, Moeini S: 
Cardiovascular risk factors in an Iranian urban population: Tehran lipid and glucose study (phase I). Soz Praventivmed 2002, 47:408-26.

18. Expert Panel on Detection, Evaluation and Treatment of High Blood Cholesterol in Adults: Executive Summary of The Third Report of The National Cholesterol Education Program (NCEP) Expert Panel on Detection, Evaluation, And Treatment of High Blood Cholesterol In Adults (Adult Treatment Panel III). JAMA 200I, 285:2486-97.

19. Grundy SM, Cleeman JI, Daniels SR, Donato KA, Eckel RH, Franklin $B A$, et al: Diagnosis and management of the metabolic syndrome: an American Heart Association/National Heart, Lung, and Blood Institute Scientific Statement. Circulation 2005, I I 2:2735-52.

20. Onat A, Sari I, Hergenç G, Yazici M, Uyarel H, Can G, Sansoy V: Determinants and definition of abdominal obesity as related to risk of diabetes, metabolic syndrome and coronary disease in Turkish men: a prospective cohort study. Atherosclerosis 2007, 191:182-90.

21. Onat A, Sari I, Hergenç G, Yazici M, Uyarel H, Can G, Sansoy V: Predictors of abdominal obesity and high susceptibility of cardiometabolic risk to its increments among Turkish women: a prospective population-based study. Metabolism 2007, 56:348-56.

22. Yang FY, Wahlqvist ML, Lee MS: Body mass index (BMI) as a major factor in the incidence of the metabolic syndrome and its constituents in unaffected Taiwanese from 1998 to 2002. Asia Pac J Clin Nutr 2008, 17:339-5I.

23. Lucove J, Vupputuri S, Heiss G, North K, Russell M: Metabolic syndrome and the development of CKD in American Indians: the Strong Heart Study. Am J Kidney Dis 2008, 5 I:2I-8.

24. Zanchetti A, Hennig M, Baurecht H, Tang R, Cuspidi C, Carugo S, Mancia G: Prevalence and incidence of the metabolic syndrome in the European Lacidipine Study on Atherosclerosis (ELSA) and its relation with carotid intima-media thickness. J Hypertens 2007, 25:2463-70.

25. Zhang H, Tamakoshi K, Yatsuya H, Murata C, Wada K, Otsuka R, Nagasawa N, Ishikawa M, Sugiura K, Matsushita K, Hori Y, Kondo T, Toyoshima $\mathrm{H}$ : Long-term body weight fluctuation is associated with metabolic syndrome independent of current body mass index among Japanese men. Circ J 2005, 69:13-8.

26. Gregg EW, Gerzoff RB, Thompson T], Williamson DF: Intentiona weight loss and death in overweight and obese U.S. adults 35 years of age and older. Ann Intern Med 2003, 138:383-9.

27. Palaniappan L, Carnethon MR, Wang Y, Hanley AJ, Fortmann SP, Haffner SM, Wagenknecht L, Insulin Resistance Atherosclerosis Study: Predictors of the incident metabolic syndrome in adults: the Insulin Resistance Atherosclerosis Study. Diabetes Care 2004, 27:788-93

28. Zabetian A, Hadaegh F, Azizi F: Prevalence of metabolic syndrome in Iranian adult population, concordance between the IDF with the ATPIII and the WHO definitions. Diabetes Res Clin Pract 2007, 77:25।-7.

29. Carroll MD, Lacher DA, Sorlie PD, Cleeman JI, Gordon DJ, Wolz M, Grundy SM, Johnson CL: Trends in serum lipids and lipoproteins of adults, 1960-2002. JAMA 2005, 294:1773-8I.

30. Sjöström L, Lindroos AK, Peltonen M, Torgerson J, Bouchard C, Carlsson B, Dahlgren S, Larsson B, Narbro K, Sjöström CD, Sullivan M, Wedel H, Swedish Obese Subjects Study Scientific Group: Lifestyle, diabetes, and cardiovascular risk factors 10 years after bariatric surgery. N Engl J Med 2004, 35 I:2683-93.

31. Esposito K, Pontillo A, Di Palo C, Giugliano G, Masella M, Marfella R, Giugliano D: Effect of weight loss and lifestyle changes on vascular inflammatory markers in obese women: a randomized trial. JAMA 2003, 289: I799-804.

32. Moore LL, Visioni AJ, Wilson PW, D'Agostino RB, Finkle WD, Ellison RC: Can sustained weight loss in overweight individuals reduce the risk of diabetes mellitus? Epidemiology 2000, I I:269-73.

33. Tuomilehto J, Lindström J, Eriksson JG, Valle TT, Hämäläinen $H$ llanne-Parikka $P$, Keinänen-Kiukaanniemi $S$, Laakso $M$, Louheranta $A$, Rastas M, Salminen V, Uusitupa M, Finnish Diabetes Prevention Study Group: Prevention of type 2 diabetes mellitus by changes in lifestyle among subjects with impaired glucose tolerance. $\mathrm{N}$ Engl J Med 200I, 344: 1343-50.
34. Villareal DT, Miller BV 3rd, Banks M, Fontana L, Sinacore DR, Klein S: Effect of lifestyle intervention on metabolic coronary heart disease risk factors in obese older adults. Am J Clin Nutr 2006, 84:13|7-23.

35. Alhassan S, Kiazand A, Balise RR, King AC, Reaven GM, Gardner CD: Metabolic syndrome: do clinical criteria identify similar individuals among overweight premenopausal women? Metabolism 2008, 57:49-56.

36. Onat A, Hergenç G, Keles I, Doğan Y, Türkmen S, Sansoy V: Sex difference in development of diabetes and cardiovascular disease on the way from obesity and metabolic syndrome. Metabolism 2005, 54:800-8.

37. de Fine Olivarius N, Richelsen B, Siersma V, Andreasen AH, BeckNielsen $\mathrm{H}$ : Weight history of patients with newly diagnosed Type 2 diabetes. Diabet Med 2008, 25:933-4I.

38. Janghorbani M, Amini M, Willett WC, Mehdi Gouya M, Delavari A, Alikhani S, Mahdavi A: First nationwide survey of prevalence of overweight, underweight, and abdominal obesity in Iranian adults. Obesity 2007, 15:2797-808.

39. Hu G, Lindström J, Valle TT, Eriksson JG, Jousilahti P, Silventoinen K Qiao Q, Tuomilehto J: Physical activity, body mass index, and risk of type 2 diabetes in patients with normal or impaired glucose regulation. Arch Intern Med 2004, 164:892-6.

40. Hadaegh F, Bozorgmanesh MR, Ghasemi A, Harati H, Saadat N, Azizi $\mathrm{F}$ : High prevalence of undiagnosed diabetes and abnormal glucose tolerance in the Iranian urban population: Tehran Lipid and Glucose Study. BMC Public Health 2008, 24(8): 176

4I. Lin KC, Tsai ST, Kuo SC, Tsay SL, Chou P: Interrelationship between insulin resistance and menopause on the metabolic syndrome and its individual component among nondiabetic women in the kinmen study. Am J Med Sci 2007, 333:208-I4.

\section{Pre-publication history}

The pre-publication history for this paper can be accessed here:

\section{http://www.biomedcentral.com/1471-2458/9/138/pre} $\underline{\mathrm{pub}}$

Publish with Biomed Central and every scientist can read your work free of charge

"BioMed Central will be the most significant development for disseminating the results of biomedical research in our lifetime. "

Sir Paul Nurse, Cancer Research UK

Your research papers will be:

- available free of charge to the entire biomedical community

- peer reviewed and published immediately upon acceptance

- cited in PubMed and archived on PubMed Centra

- yours - you keep the copyright 